\title{
ASSOCIAÇÕES ENTRE O ISOLAMENTO DE Candida albicans COM A INFECÇÃO PELO VÍRUS DA LEUCEMIA FELINA (FeLV), TRATAMENTOS COM CORTICOSTERÓIDES OU ANTIMICROBIANOS EM GATOS*
}

\author{
STUDY OF THE ASSOCIATIONS BETWEEN THE ISOLATION OF Candida albicans AND INFECTION BY THE \\ FELINE LEUKEMIA VIRUS (FeLV), TREATMENT WITH CORTICOSTEROIDS OR ANTIMICROBIALS IN CATS
}

\author{
Laerte Ferreiro ${ }^{1}$, João Pessoa Riograndense Moreira Jr. ${ }^{2}$, Carin Elisabete Appelt ${ }^{3}$, Vanessa Berg ${ }^{3}$, Izamara \\ Aparecida de Oliveira ${ }^{3}$, Adriana Cunha Muschner ${ }^{4}$, Dilmara Reischak ${ }^{5}$ \& René Chermette $^{6}$
}

\section{RESUMO}

Candida albicans, integrante da microbiota normal do trato intestinal de muitos mamíferos e aves, raramente é isolada da pele de animais saudáveis, contudo, alterações no sistema imune podem favorecer o seu desenvolvimento. Para verificar possíveis associações com o vírus da leucemia felina (FeLV), tratamentos com corticosteróides ou antimicrobianos e outros parâmetros, foram obtidas 150 amostras do pelame e das mucosas bucal e anal de gatos da região metropolitana de Porto Alegre, RS. Os diversos materiais foram cultivados em ágar Sabouraud suplementado com cloranfenicol. O sangue foi examinado através da imunofluorescência indireta (IFA). $\mathrm{O}$ único fungo isolado foi Candida albicans: $8,7 \%$ (mucosa bucal), 6,7\% (pele) e $1,3 \%$ (mucosa anal). O teste IFA detectou $24,7 \%$ (37) gatos soropositivos. O teste do Qui-Quadrado indicou associações significativas entre presença de Candida albicans na pele ou na mucosa bucal e : infecção por FeLV; terapia (até 60 dias anteriores à obtenção dos materiais) com antimicrobianos ou corticosteróides; lesões na mucosa bucal; lesões na pele e, linfonodos mandibulares aumentados. Por outro lado, não houve associação entre Candida albicans na pele ou na mucosa bucal com idade, sexo, raça, habitat ou presença de diarréia. A análise de regressão logística, indicou que as chances de isolamento da mucosa bucal e da pele são, respectivamente 8,8 e 5,3 vezes maiores nos gatos soropositivos e, 6,8 e 9,8 vezes maiores naqueles previamente tratados com antimicrobianos. As chances de isolamento são ainda mais altas, isto é, 13,4 (mucosa bucal)e 16,0 (pele) vezes maiores nos gatos sob corticoterapia. Embora existam observações contraditórias, os resultados obtidos, sugerem que a presença da levedura esteja freqüientemente relacionada a uma depressão do sistema imune, pois os gatos FeLV positivos sintomáticos, ou aqueles tratados com corticosteróides, foram os mais susceptíveis à colonização por Candida albicans.

Descritores: Candida albicans, FeLV, gatos, imunodepressão, antimicrobianos, corticosteróides.

\begin{abstract}
Candida albicans is commonly found in the intestinal tract of most mammals and birds, but its isolation in the skin of healthy animals has been rarely reported. However, when the host's immune defenses are impaired, the colonization by this yeast is possible. The possibilities of associations between C. albicans, feline leukemia virus (FeLV) and others parameters were investigated. Samples from the oropharyngeal and ano-rectal mucosa, fur coat, and blood were collected from 150 cats in the metropolitan area of Porto Alegre, Brazil. Samples were cultivated in Sabouraud's agar supplemented with chloramphenicol. Blood samples were also tested for FeLV by indirect immunofluorescence (IFI). Candida albicans was isolated from the oropharyngeal mucosa $(8.7 \%)$, fur coat $(6.7$ $\%)$, and rectal mucosa $(1.3 \%)$. Thirty-seven $(24.7 \%)$ cats were FeLV-seropositives. The $\chi^{2}$ test revealed significant associations between the $C$. albicans in the skin or oral mucosa and FeLV infection, antimicrobial or corticosteroid therapy 60 days prior to sample collection, and presence of lesions in the oral mucosa. There were no significant associations between C. albicans in the skin or oral mucosa and age, sex, breed, habitat or occurrence of diarrhea. A logistical regression analysis verified that seropositive or antimicrobial-treated animals were 8.8- and 5.3-, and 6.8- and 9.8-fold more susceptible to have a positive isolation of $C$. albicans from the oral mucosa and skin, respectively, than seronegative or non-treated animals; in addition, the corticosteroid therapy appeared to have increased the incidence of $C$. albicans isolation in the oral mucosa and skin by 13.4- and 16.0-fold. Data described in the literature are controversial, but these results suggest that the isolation of $C$. albicans may be dependent on the degree of immunosupression in each animal, since seropositive and antimicrobial- or corticosteroid-treated cats were significantly more susceptible to be colonized by Candida albicans.
\end{abstract}

Key words: Candida albicans, FeLV, cats, immunosupression, antimicrobials, corticosteroids.

\footnotetext{
* Trabalho originado da Dissertação de Mestrado do segundo autor. ${ }^{1}$ Setor de Micologia, Departamento de Patologia Clínica Veterinária FAVET/ UFRGS. ${ }^{2}$ Programa de Pós-Graduação em Ciências Veterinárias (PPGCV) - FAVET/UFRGS. ${ }^{3}$ Estagiária do Setor de Micologia.

${ }^{4}$ Bolsista PROREXT-UFRGS (Setor de Micologia). ${ }^{5}$ Setor de Virologia, DPCV - FAVET/UFRGS. ${ }^{6}$ Service de Parasitologie-Mycologie, Ecole Nationale Vétérinaire d'Alfort (ENVA), Maisons-Alfort, France.

CORRESPONDÊNCIA: L. Ferreiro [e-mail: laerte.ferreiro@ufrgs.br ; FAX: +55 513316 7305]. Setor de Micologia - DPCV/FAVET/UFRGS. Caixa Postal 15094; 91501-970 Porto Alegre, RS - Brasil.
} 


\section{INTRODUÇÃO}

Candida albicans apesar de fazer parte da microbiota normal do trato intestinal, pode se constituir em patógeno oportunista das regiões mucocutâneas, trato digestivo e genital de mamíferos e aves, além de envolver pele, unhas e trato respiratório com riscos de desencadear fungemias. A candidose como doença primária, é extremamente rara, e via de regra está associada a neoplasias, doenças imunomediadas e ao uso prolongado de corticosteróides, antimicrobianos ou citostáticos [8].

Os estados de imunodeficiências induzidas por infecções virais no gato como rinotraqueíte, peritonite infecciosa felina, imunodeficiência felina (FIV) e leucemia felina (FeLV) podem se constituir em causas predisponentes às infecções fúngicas como a candidose [3,17].

As doenças secundárias nos gatos infectados com o vírus da leucemia felina compartilham muitas semelhanças biológicas com quadros clínicos associados à síndrome da imunodeficiência adquirida (SIDA) nos humanos [14], onde é notória a incidência de candidoses $[6,8]$.

Os objetivos do trabalho foram verificar associações entre o isolamento de Candida albicans com a detecção do vírus da FeLV, com o uso prévio de antimicrobianos ou de corticosteróides. Buscou-se verificar também uma possível relação entre a presença desta levedura com sexo, idade, raça, habitat e outros parâmetros.

\section{MATERIAIS E MÉTODOS}

Cento e cinqüenta gatos procedentes da grande Porto Alegre, foram submetidos a exame clínico, acompanhado de colheita de sangue, para pesquisa do vírus da FeLV, durante o período de julho de 2000 a fevereiro de 2001. Dos mesmos animais foram colhidos raspados das mucosas orais, anais e de pêlos para o isolamento fúngico.

Os animais foram classificados de acordo com a idade, sexo, raça, procedência, manifestações clínicas, sintomatologia, administração de antimicrobianos e corticosteróides, lesões de pele e da mucosa bucal.

Animais: 71 (47,3\%) eram machos e 79 (52,7\%) fêmeas. A idade estava assim distribuída: $34(22,7 \%)$ animais com idade inferior a 12 meses; $54(36,0 \%)$ entre 13 e 60 meses; 17 (11,3\%) entre 61 e 120 me- ses; $4(2,7 \%)$ entre 121 e 180 meses e $41(27,3 \%)$ com idade desconhecida.

Os gatos foram classificados conforme a raça e o comprimento do pelo: $79(52,7 \%)$ animais sem raça definida de pelo curto (SRDC), 36 (24,0\%) persas, 26 $(17,3 \%)$ animais sem raça definida pelo longo (SRDL) e $9(6,0 \%)$ siameses.

Quanto à procedência da população amostrada: $67(44,6 \%)$ domiciliados, $46(30,7 \%)$ de rua e 37 $(24,7 \%)$ eram animais de gatis.

Amostras do pelame: foram obtidas através da técnica do carpete estéril [11], que foi friccionado em todo o corpo dos animais que não apresentavam lesões de pele aparentes. Nos animais com problemas de pele, o carpete foi utilizado somente nas áreas das lesões.

Amostras da mucosa bucal e anal: num projeto piloto comparou-se os cultivos obtidos através de swabs com aqueles obtidos através de cureta estéril das amostras da mucosa bucal. Observou-se que a coleta com cureta proporcionou um número maior de isolamentos. Havendo lesões aparentes, o material era coletado da própria lesão e rapidamente processado. $\mathrm{Na}$ mucosa anal foi utilizado swab estéril.

Identificação dos fungos: os materiais obtidos foram cultivados em meio de ágar Sabouraud dextrose ${ }^{1}$ acrescido de $0.5 \mathrm{~g} / \mathrm{L}$ de cloranfenicol ${ }^{2}$ a $37{ }^{\circ} \mathrm{C}$, durante 5 dias. Para a identificação da espécie utilizou-se o teste do tubo germinativo em soro equiino e a produção clamidósporos em agar fubá.

Técnica da imunofluorescência indireta (IFI): aproximadamente $1 \mathrm{~mL}$ de sangue, após coagulado, era centrifugado a $2.500 \mathrm{rpm} / \mathrm{min}$. durante 2 minutos. Uma alíquota de $50 \mathrm{ml}$ de soro era utilizada para o preparo de dois esfregaços, que eram secos à temperatura ambiente. Os reagentes utilizados (soros anti-FeLV e anti-IgG conjugado) fazem parte do teste diagnóstico da leucemia felina (FeLV Dectectin Set ${ }^{3}$ ).

Análise estatística: os resultados da cultura fúngica e da IFI foram cruzados em tabelas $2 \times 2$ entre si e com as variáveis observadas na ficha clínica, utilizando-se o teste do Qui-quadrado com significância estatística de $\mathrm{p} \leq 0,05$, teste de Fischer e Monte Carlo (quando as caselas eram menores do que cinco). Utilizou-se também o exame dos resíduos ajustados como uma análise complementar ao teste do Qui-quadrado 
para verificar quais variáveis estavam associadas significativamente com o isolamento da levedura. Também foi realizada a regressão logística para determinação da razão de chances.

\section{RESULTADOS}

O exame clínico dos 150 gatos revelou que 23,3\% (35) tinham lesões de pele, 20,7\% (31) mucosas pálidas, 17,3\% (26) diarréia, 17,3\% apatia, 13,3\% (20) lesões na mucosa bucal e $11,3 \%$ (17) linfonodos aumentados.

O teste da IFI detectou que $24,7 \%$ (37) eram soropositivos e 75,3\% (113) negativos para o vírus da leucemia felina.

O único fungo isolado foi Candida albicans: $8,7 \%$ (13) na mucosa bucal, $6,7 \%$ (10) na pele e $1,3 \%$ (2) na mucosa anal.

Num período de até 60 dias anteriores a coleta das amostras, $22,7 \%$ (34) dos animais tinham recebido antimicrobianos e 12,0\% (18) corticosteróides.

A avaliação estatística através do Qui-quadrado permitiu observar várias associações significativas, tais como presença de Candida albicans na: mucosa bucal $(p<0,001)$ ou pele $(p=0,007)$ e animais FeLV soropositivos; mucosa bucal $(\mathrm{p}<0,001)$ ou pele $(\mathrm{p}<0,001)$ e administração prévia de antimicrobianos; mucosa bucal $(\mathrm{p}<0,001)$ ou pele $(\mathrm{p}<0,001)$ e administração prévia de corticosteróides; mucosa bucal $(p<0,001)$ ou pele $(p<0,001)$ e apatia; mucosa bucal $(\mathrm{p}<0,001)$ ou pele $(\mathrm{p}=0,003)$ e mucosas pálidas; mucosa bucal $(\mathrm{p}=0,001)$ ou pele $(\mathrm{p}=0,003)$ e linfonodos mandibulares aumentados; mucosa bucal $(\mathrm{p}<0,001)$ ou pele $(\mathrm{p}<0,001)$ e lesões na mucosa bucal. Também ocorreu associação entre isolamento da levedura da pele $(\mathrm{p}<0,001)$ versus lesões de pele.

Por outro lado, não houve diferença significativa entre o sexo dos gatos e a presença da $C$. albicans na mucosa bucal $(\mathrm{p}=0,283)$ ou na pele $(\mathrm{p}=0,406)$; entre a idade e o isolamento da levedura na mucosa bucal $(p=0,692)$ ou na pele $(p=0,879)$; entre raça versus presença de $C$. albicans na mucosa bucal $(\mathrm{p}=$ $0,551)$ ou na pele $(p=0,454)$; entre o habitat dos animais estudados e o número de casos culturas positivas isoladas tanto da mucosa bucal $(p=0,022)$ quanto da pele $(\mathrm{p}=0,798)$; entre os animais com diarréia versus presença de $C$. albicans na mucosa bucal ( $\mathrm{p}=$ $0,181)$ ou na pele $(\mathrm{p}=0,273)$. Também não ocorreu associação entre lesão de pele versus presença de $C$. albicans na mucosa bucal $(\mathrm{p}=0,058)$.

Através do emprego de regressão logística verificou-se que as chances de ocorrer isolamento de Candida albicans das amostras obtidas da mucosa bucal e da pele de um gato FeLV positivo, eram respectivamente 8,8 e 5,3 vezes maiores do que a partir de animal FeLV negativo. As chances de isolamento de $C$. albicans da mucosa bucal e da pele de um gato que tinha sido medicado com antimicrobianos, eram respectivamente, de 6,8 e 9,8 vezes maiores do que daquelas oriundas de animal não tratado. Da mesma forma, as chances de isolamento de $C$. albicans da mucosa bucal e da pele de um gato anteriormente medicado com corticosteróides, eram respectivamente, de 13,4 e 16,0 vezes maiores do que de um animal sem este tratamento.

\section{DISCUSSÃO}

Candida albicans foi isolada em 6,7\%, 8,7\% e $1,3 \%$ das amostras da pele, mucosas bucal e anal. Estes resultados são similares aos de Sierra et al. [18], que encontraram nos mesmos sítios porcentuais 9,3\%, $5,8 \%$ e $0 \%$. Outros pesquisadores que estudaram somente a microbiota da pele de gatos saudáveis, ou não isolaram a levedura [4], ou observaram apenas uma baixa prevalência da mesma [13].

A literatura fornece resultados contraditórios, já que existem indícios de que a condição de soropositividade para FeLV e FIV (duas viroses com potencial imunossupressor) não tem influência na freqüência de isolamento da C. albicans [18], muito embora quando foram comparados animais doentes com animais saudáveis, a microbiota da mucosa bucal foi significativamente mais diversificada nos animais FeLV e FIV sintomáticos do que nos assintomáticos. Já outros autores [10], a isolaram de $23 \%$ dos gatos FIV soropositivos e de apenas $4 \%$ dos não infectados. Além disso, C. albicans foi isolada de 30,8\% dos gatos FIV sintomáticos, mas de nenhum dos assintomáticos.

Neste estudo, C. albicans foi isolada da mucosa bucal de 24,3\% dos gatos FeLV infectados e, de apenas 3,5\% dos não infectados. Na pele, a levedura foi isolada de $16,2 \%$ dos FeLV soropositivos e, de somente 3,53\% dos negativos. Estes dados sugerem que a soropositividade para esta virose tenha re- 
lação com o isolamento da levedura, tanto da mucosa bucal quanto da pele. Também é importante salientar que os gatos FeLV positivos que apresentavam sintomatologia relacionada com a virose, albergavam C. albicans na mucosa bucal (31\%) e na pele (20,7\%). Estes resultados estão de acordo com observações anteriores sobre o fato das micoses oportunistas ocorrerem mais freqüentemente quando as defesas do hospedeiro estiverem comprometidas $[6,10]$.

$\mathrm{O}$ vírus da leucemia felina tem sido associado a uma série de disfunções no sistema imune e, conseqüentemente, a sinais clínicos muito variáveis [17]. O fator que nos parece fundamental elucidar é se o mesmo está afetando o sistema imune ou não, visto que os gatos infectados podem permanecer assintomáticos por semanas ou meses [5], e mesmo assim, terem uma eficaz reação imune e não desenvolver a doença apesar do estado virêmico ter persistido por um longo período [9].

Em medicina humana, a candidose oral é uma das primeiras infecções observada em pacientes portadores do vírus HIV, sendo por isto considerada marcador de imunodeficiência $[2,15,16]$. Em um estudo [12], 60\% dos pacientes infectados com HIV desenvolveram candidose oral evidenciando a metade do número de linfócitos em relação aos pacientes normais o que explica as freqüentes recidivas de candidose oral. Também tem sido relatado um aumento da colonização por $C$. albicans, na proporção direta ao desenvolvimento da síndrome da imunodeficiência adquirida (SIDA) [7].

Os resultados aqui obtidos indicam que manifestações clínicas, como apatia e mucosa pálida, têm associação significativa com o isolamento de $C$. albicans tanto da mucosa bucal, quanto da pele. Estas observações corroboram as citações da literatura sobre a candidose, tanto oral quanto cutânea, ocorrer geralmente em animais debilitados e anêmicos [1,17].

Sob outro enfoque, verificou-se que a administração de antimicrobianos ou de corticosteróides, até 60 dias antes da coleta das amostras, influenciou significativamente no isolamento da $C$. albicans, tanto da mucosa bucal quanto da pele. Esta constatação está de acordo com trabalhos que apontam estas drogas como fatores predisponentes para a instalação da candidose em animais [1,17]. Estes medicamentos também já foram relacionados como causas favorecedoras da instalação do quadro de candidose em humanos $[2,15]$.
Acompanhando o avanço da medicina humana, as micoses oportunísticas, notadamente as candidoses, tornaram-se freqüente causa de óbitos em pacientes com leucemia, linfomas, tumores e trasnsplantados, onde a leucopenia é um fator de risco sempre presente. Por outro lado, na SIDA, onde a imunossupressão está mais relacionada aos linfócitos, as candidoses representam $70-80 \%$ das micoses, todavia, como a leucopenia é menos severa, os óbitos pelas candidoses são em menor número [12].

Em medicina veterinária, particularmente em relação aos gatos, as candidoses têm sido raramente relatadas $[13,19]$. Neste contexto, os resultados obtidos sugerem que o isolamento de $C$. albicans está relacionado com imunodepressão, pois, os animais FeLV positivos, com sintomatologia da doença ou que estavam sendo tratados com drogas imunossupressoras, foram mais susceptíveis à colonização pela $C$. albicans, tanto na mucosa bucal quanto na pele.

\section{CONCLUSÕES}

A análise das interações estudadas permitiu concluir que houve associação significativa entre o isolamento de Candida albicans e a detecção do vírus da FeLV, e que a administração de antimicrobianos e corticosteróides nos 60 dias anteriores a coleta das amostras favoreceu significativamente o isolamento desta levedura. Contrariamente, não houve associação significativa entre sexo, idade, raça, habitat ou gatos com diarréia em relação ao isolamento de $C$. albicans.

Por outro lado, manifestações clínicas como apatia, mucosas pálidas, linfonodos mandibulares aumentados e lesões de mucosa bucal mostraram-se significativamente associadas a uma maior probabilidade de isolamento de C. albicans.

Em virtude destas conclusões, a investigação epidemiológica,através da mensuração dos parâmetros de prevalência e incidência da candidose, associada aos fatores predisponentes, é condição fundamental para uma melhor avaliação da importância desta micose na clínica de pequenos animais.

\section{NOTAS INFORMATIVAS}

${ }^{1}$ Acumedia Manufacturers Inc., Baltimore, Maryland, 21220, USA.

${ }^{2}$ Dyne - Quimibrás Indústrias Químicas S. A., Rio de Janeiro, Brasil.

${ }^{3}$ VMRD Inc., P. O. 502, Pullman, WA, 99163, USA. 


\section{REFERÊNCIAS}

1 Dunn J.K. 2001. Dermatopatias caninas e felinas Candidíase. In: Tratado de Medicina de Pequenos Animais. São Paulo: Roca, p.882.

2 Fotos P. G \& Hellstein J. W. 1992. Candida and candidosis: epidemiology, diagnosis and therapeutic management. Dental Clinics of North America. 36: 857878.

3 Gallo M. G., Bo S., Ponzio P., Isaia M. C. \& Buracco P. 1991. Mycoses et immunodepression chez l'animal de compagnie: expérience dans la ville de Turin (Italie). In: Résumés du Congrès de la Sociétè Française de Micologie Médicale (Tours, France). pp. 24 - 25.

4 Gambale W., Larsson C. E., Moritami M. M., Corrêa B., Rodrigues C. P. \& Souza V. M. F. 1993. Dermatophytes and other fungi of the haircoat of cats without dermatophytoses in the city of São Paulo, Brazil. Feline Practice. 21: 29-33.

5 Hardy Jr W. D., Hess P. W. \& Macewen E. G. 1976. Biology of feline leukemia virus in the natural environment. Cancer Research. 36: 582-588.

6 Kibbler C.C. 1996. Fungaemia and disseminated fungal infection. In: Kibbler C.C., Mackenzie D.W.R. \& Odds F.C. (Eds). Principles and Practice of Clinical Mycology. West Sussex: John Wiley Sons Ltd., pp. 143-164.

7 Korting H. C., Ollert M., Georgii A. \& Froschl M. 1988. In vitro susceptibilities and biotypes of Candida albicans isolates from the oral cavities of patients infected with human immunodeficiency virus. Journal of Clinical Microbiology. 26: 2626-2631.

8 Kwon-Chung K. J. \& Bennett J. E. 1992. Epidemiology. In: Kwon-Chung K.J.\& Bennett J. E. (Eds). Medical Mycology. Philadelphia: Lea and Febiger, pp. 35-43.

9 Lutz N. \& Jarret O. 1987. Detection of feline leukemia virus infection in saliva. Journal of Clinical Microbiology. 25: 827.

10 Mancianti F., Gianelli C., Bendinelli M. \& Polo A. 1991. Mycological findings in feline immunodeficiency virus infected cats. Journal of Medical and Veterinary Mycology. 30: 257-259.

11 Mariat F. \& Adan-Campos C. 1967. La technique du carré de tapis, méthode simple de prélèvement dans le mycoses superficielles. Annales de l' Institut Pasteur.113: 666-669.

12 Mautoni M. C. 1997. Estudo clínico, laboratorial e terapêutico da candidose oral em pacientes com sistema imunológico deprimido pelo HIV. 52f. São Paulo, SP.Tese (Doutorado em Odontologia) - Faculdade de Odontologia, Universidade do Estado de São Paulo.
13 Moriello K. A. \& DeBoer D. J. 1991. Fungal flora of the coat of pet cats. American Journal of Veterinary Research. 52: 602-606.

14 Norsworthy G. D. 1993. Feline immunodeficiency virus diseases. In: Feline practice. Philadelphia: Lippincott Co., pp. 348-351.

15 Samaranayake L.P. 1992. Oral mycoses in HIV infection. Oral Surgery Oral Medicine Oral Pathology Oral Radiology and Endodontics. 73: 171-180.

16 Scully C. 1992. Oral infection in the immunocompromised patient. British Dental Journal. 172: 401-407.

17 Sherding R. G. 1998. Vírus da Leucemia Felina. In: Birchard, S. J.\& Sherding, R. G. (Eds). Manual Saunders - Clínica de Pequenos Animais. São Paulo: Roca, pp. 91-100.

18 Sierra P., Guillot J., Jacob H., Bussiéras S. \& Chermette R. 2000. Fungal flora on cutaneous and mucosal surfaces of cats infected with feline immunodeficiency virus or feline leukemia virus. American Journal of Veterinary Research. 61: 158-161.

19 Willemse T. 1998. Doenças fúngicas / Candidíase. In: Dermatologia Clínica de Cães e Gatos. 2.ed. São Paulo: Editora Manole, p. 21. 